\title{
A CONTINUAÇÃO DO DIREITO NATURAL, A CONTINUAÇÃO DA GUERRA E O PAPEL DAS UNIVERSIDADES EM ESPINOSA E FOUCAULT ${ }^{*}$
}

Fernando Bonadia de Oliveira*

\begin{abstract}
RESUMO
A afirmação de Espinosa (1632-1677) pela continuação do direito natural e a defesa de Foucault (1926-1984) por uma política que seja concebida como guerra contínua são os eixos a partir dos quais cada um desses filósofos busca se afastar da filosofia política de Hobbes (1588-1679). Refutando o modelo do "Leviatã", Espinosa e Foucault apresentam considerações sobre a política que, respeitadas as diferenças patentes de contexto histórico, podem ser aproximadas. Essa aproximação se revela também na consideração de ambos acerca do papel desenvolvido pelas universidades. Mostrar, portanto, como Espinosa e Foucault se distinguem de Hobbes a partir de alguns fragmentos de suas obras e evidenciar qual é o papel das universidades apontado por esses dois filósofos, nisso consiste o escopo deste artigo.
\end{abstract}

PALAVRAS-CHAVE: Direito Natural e Guerra. Universidade. Espinosa, B. (1632-1677). Foucault, M. (1926-1984). Filosofia da Educação.

\footnotetext{
* Este texto corresponde à versão ampliada e revisada da comunicação apresentada no III Colóquio Franco-Brasileiro de Filosofia da Educação: Foucault 80 anos, realizado na Universidade Estadual do Rio de Janeiro (UERJ), nos dias 9, 10 e 11 de outubro de 2006.

** Mestrando em História e Filosofia da Educação pela UNICAMP. E-mail: fernandobonadia@yahoo.com.br
} 


\begin{abstract}
Espinosa's affirmation for the continuation of the natural right and Foucault's defense for a politics conceived as a continuous war are the axis from where one of these philosophers tries to get away from Hobbes politics philosophy. Refuting the Leviathan's model, Espinosa and Foucault present considerations about the politics that, respecting the patent differences of the historical context, could be approximated. This approuch reveals itself also in both considerations about the role played in the Universities. Therefore, showing how Espinosa and Foucault distinguish themselves from Hobbes from some fragments of his work and evidence which is the University role pointed by these two philosophers consist the purpose of this article.
\end{abstract}

KEYWORDS: Natural Right and War. University. Espinosa, B. (1632-1677). Foucault, M. (1926-1984). Philosophy of Education.

\title{
Introdução
}

Thomas Hobbes (1588-1679) é o filósofo do qual tanto Bento de Espinosa (1632-1677) quanto Michel Foucault (1926-1984) se afastam para engendrar suas próprias concepções sobre a política. Espinosa, contemporâneo de Hobbes, explicitou a diferença entre a sua concepção política e aquela apresentada pelo filósofo inglês na "Carta n $\mathrm{n}^{\circ}$ " de Correspondência, redigida a 2 de junho de 1674. Foucault, por sua vez, desenvolveu sua mais detalhada análise do pensamento filosófico-político de Hobbes (contra o qual se coloca rechaçando sua concepção filosófico-jurídica) em seu curso Em Defesa da Sociedade, mais precisamente na aula de 4 de fevereiro de 1976, portanto quase trezentos anos após a morte do autor de Leviatã.

Este trabalho tem como objetivo revelar como Espinosa e Foucault, cada um a seu modo, em seus específicos contextos históricos e mediante seus esquemas próprios de investigação da

Educ. e Filos., Uberlândia, v. 22, n. 43, p. 63-87, jan./jun. 2008.

64 
realidade, afastam-se do pensamento político hobbesiano. Também pretende evidenciar a forma extremamente similar pela qual concebem o papel desenvolvido pelas universidades.

Como, todavia, um trabalho com tais objetivos necessita de uma delimitação para não incorrer em afirmações e conclusões demasiadamente vagas, as análises que aqui serão expostas foram restringidas, no tocante a Espinosa, às considerações apresentadas em seus dois tratados (o Tratado Político e o Tratado TeológicoPolítico), especificamente nos fragmentos em que são abordadas as noções de "direito civil" e "direito natural"; ademais, será abordada também a passagem do Tratado Político em que Espinosa faz uma importante colocação sobre as academias instituídas às custas do Estado. No tocante a Foucault, este trabalho limitar-se-á às suas considerações constantes na supracitada aula de 4 de fevereiro de 1976 do curso em Defesa da Sociedade (em que o filósofo contemporâneo francês expõe sua reflexão sobre o pensamento político de Hobbes) e na aula de 25 de fevereiro (em que ele examina o papel de seleção dos saberes desenvolvido pelas universidades a partir do século XVIII). Ademais, será tomada uma breve citação de $A$ Verdade e as Formas Jurídicas, de 1973.

Não haverá, porém, um aprofundamento no próprio pensamento expresso nas obras de Hobbes, isto é, o pensamento causador das dissensões, pois este estudo limita-se a explanar sobre o que Espinosa e Foucault construíram a partir da crítica a Hobbes e não a revelar o que fora, de fato, escrito por ele ${ }^{1}$. Portanto, este trabalho apenas se remeterá à obra hobbesiana quando ela for relevante para o esclarecimento de alguma referência a Hobbes feita pelos autores aqui tomados.

1 Talvez as leituras de Hobbes empreendidas por Espinosa e Foucault causem discordâncias entre os estudiosos contemporâneos do pensamento político hobbesiano. Seria sumamente interessante que fosse realizado, futuramente, um estudo visando confrontar aquilo que dizem os dois intérpretes de Hobbes aqui abordados com aquilo que, de fato, encontra-se no texto do pensador inglês. Tal problemática, porém, não faz parte deste trabalho. 


\section{A continuação do direito natural: Espinosa contra Hobbes}

A "Carta $\mathrm{n}^{\circ}$ 50" de Espinosa, remetida a Jarig Jelles em 2 de junho de 1674, inicia-se da seguinte maneira:

Relativamente à política (Quantum ad politicam spectat), tu me perguntas qual é a diferença entre a minha e a de Hobbes. Respondo-te: a diferença consiste em que mantenho (conservo) sempre o direito natural e que considero que o magistrado supremo, em qualquer cidade, só tem direito sobre os súditos na medida em que seu poder seja superior ao deles; coisa que sempre ocorre no estado natural (ESPINOSA, 1979, p. 392)"2.

Ao colocar sua resposta a Jelles, Espinosa facilmente permite perceber que o estado civil é tomado por ele como uma continuação do estado natural ${ }^{3}$. Além disso, a partir desse importante fragmento da correspondência espinosana é possível desde já supor que, conquanto a distinção apontada por Espinosa pareça pequena à primeira vista, ela implica em grandes diferenças, se se considerar que é justamente a articulação do direito natural e do direito civil que promove o nascimento da vida política (CHAUÍ, 2003a, p. $289)^{4}$. Ademais, deve ser notado que a afirmação de Espinosa, embora apresente a distinção entre a sua filosofia política e a de Hobbes, também parece partir de uma leitura equivocada de Hobbes, uma vez que este último afirma a conservação do direito natural em dois sentidos: por meio do "silêncio das leis" e como "virtualidade" (HOBBES, 1968, p. 270-271) 5 . Todavia, como

2 A tradução deste fragmento da "Carta $n^{\circ}$ 50" foi levemente modificada a partir da tradução feita por Marilena Chauí (ESPINOSA, 1979, p. 392), conforme a citação.

3 Cf. Nota da tradução no 37 de Marilena Chauí (ESPINOSA, 1979, p. 392).

4 Este texto de Marilena Chauí é fundamental para que se compreenda como se articulam as similitudes e discrepâncias entre as concepções filosóficas e políticas de Espinosa e Hobbes.

5 Na Parte II, Capítulo 21 "Of the Liberty of Subjects", Hobbes afirma que o direito natural permanece em dois casos: quando as leis silenciam e nada é

Educ. e Filos., Uberlândia, v. 22, n. 43, p. 63-87, jan./jun. 2008. 
observa Marilena Chauí (2003a, p. 296), são exatamente esses dois sentidos que Espinosa considera como sua não-conservação.

A diferença apontada por Espinosa entre a sua filosofia política e a de Hobbes parte, antes, de uma diferença de concepção entre direito e lei (jus e lex). Enquanto Hobbes distingue direito de natureza e lei de natureza ${ }^{6}$, Espinosa torna tais termos equivalentes, o que se percebe logo no início do capítulo XVI de seu Tratado Teológico-Político (TTP) ou no quarto parágrafo do segundo capítulo de seu Tratado Político (TP).

No TTP (Capítulo XVI), acha-se dito:

Por direito (jus) e instituição natural (institutum naturae) entendo unicamente as regras da natureza (regulas naturae) de cada indivíduo, regras segundo as quais concebemos qualquer ser como naturalmente determinado a existir e a agir de uma certa maneira ${ }^{7}$.

No TP (Capítulo II) acha-se - por sua vez - escrito:

por direito natural (jus naturae), portanto, entendo as próprias leis ou regras da natureza (ipsas naturae leges seu regulas) segundo as quais tudo acontece, isto é, a própria potência da natureza (ipsam naturae potentiam ${ }^{8}$.

fixado pelo soberano como regra a ser seguida e enquanto existe nos homens uma virtualidade capaz de vir a atualizar-se e resultar em guerra civil.

6 Tal distinção hobbesiana entre direito e lei fica explícita nas primeiras linhas do Capítulo 14 "Of the First and Second Naturall Lawes, and of Contracts" do Leviatã. Escreve Hobbes, portanto, que embora muitos confundam direito e lei, é necessário assentar que o direito consiste (consisteth) em liberdade de fazer ou de omitir (to do, ou to forbeare), enquanto a lei determina e obriga (determineth, and blindeth) a um dos dois. A diferença entre direito e lei é da ordem da distinção entre liberdade e obrigação, as quais são - no arremate do autor incompatíveis quando se trata de uma e mesma matéria (same matter).

7 Na tradução de Diogo Pires Aurélio (ESPINOSA, 1988) utilizada aqui, o trecho se encontra na página 308 .

8 As traduções do Tratado Político disponíveis ao público brasileiro (a de José Perez - Ediouro -, a de Norberto de Paula Lima - Editora Ícone - e a de Manuel de Castro - Editora Abril, Coleção Os Pensadores) traduzem a palavra aqui incidente "potentiam" por poder. Ainda que tal tradução possa eventualmente 
A forma como Espinosa continua sua definição de direito natural é muito similar nos dois tratados. Em ambos, o filósofo resume um longo trajeto argumentativo exposto, de forma mais acabada, na sua Ética.

Tomando o TTP como eixo de leitura, vê-se que Espinosa, após definir pontualmente o direito natural, segue afirmando:

É, com efeito, evidente que a natureza, considerada em absoluto, tem direito a tudo o que está em seu poder, isto é, o direito da natureza estende-se até onde se estende a sua potência, pois a potência da natureza é a própria potência de Deus, o qual tem direito a tudo. Visto, porém, que a potência universal de toda a natureza não é mais do que a potência de todos os indivíduos em conjunto, segue-se que cada indivíduo tem pleno direito a tudo o que está em seu poder, ou seja, o direito de cada um estende-se até onde se estende a sua exata potência (TTP, Capítulo XVI) .

Conforme revela Marilena Chauí (2003b, p. 225, nota $n^{\circ} 20$ ) comentando a leitura do TP, há uma dificuldade nas sínteses de Espinosa que, como essa, resumem longos trajetos argumentativos desenvolvidos por ele e que tomam como dados alguns conceitos próprios da sua ontologia. Para explicar, portanto, cada passo argumentativo de Espinosa na citação acima seria necessário resgatar diversos conceitos apresentados nas primeiras quatro partes da Ética, o que é impossível fazer em espaço tão limitado.

justificar-se fora da obra de Espinosa, ela parece ser imprópria em se tratando do pensamento do filósofo holandês. Neste caso, a palavra merecedora da tradução "poder" é "potestas" e não "potentia". Espinosa trabalha com a questão "poder e potência" de Deus na Ética, Parte I, Proposição 11, Demonstração. Cf., por exemplo, Ética, Parte IV, definição 6, onde se lê: "por virtude e potência entendo a mesma coisa (Per virtutem et potentiam idem intelligo)". Deleuze (s/d, p. 116-126), Marilena Chauí (1999, p. 916), entre outros comentadores também trabalham com esta distinção entre "potestas" (como poder) e "potentia" (como potência). Antonio Negri (1993), no subtítulo de seu livro A Anomalia Selvagem joga com os dois conceitos "poder e potência em Spinoza".

9 Na tradução de Diogo Pires Aurélio (ESPINOSA, 1988) utilizada aqui, o trecho se encontra na página 308.

Educ. e Filos., Uberlândia, v. 22, n. 43, p. 63-87, jan./jun. 2008. 
Espinosa, como se vê, afirma que a natureza tem direito a tudo o que está em seu poder (ou seja, que seu direito estende-se até onde se estende sua potência), pois a potência da natureza é a própria potência de Deus (que tudo pode). O filósofo observa também que a potência universal de toda a natureza não é senão a potência de todos os indivíduos conjuntamente e que, portanto, o direito de cada indivíduo se estende até onde sua exata potência se estende. Se cada indivíduo tem direito a tudo quanto pode, qual é, então, a função do direito civil espinosano?

A resposta que Espinosa oferece a seus leitores é a de que o direito civil é a condição de existência real do direito natural, de modo que ele só é necessário para fazer valer até o fim o direito natural dos homens. No TP, tal exposição aparece com a seguinte concatenação: a natureza do homem não é tal que ele viva unicamente sob as prescrições da razão, ao contrário, segundo Espinosa, os homens são mais conduzidos pelo desejo cego do que pela razão. Conseqüentemente, a potência ou direito (potentia sive ius) natural dos seres humanos deve ser definido pelo apetite (ou desejo) ${ }^{10}$ que não só os determina a agir, mas que também é aquele através do qual todos se esforçam para conservar a si mesmos. Para Espinosa, portanto, quer sejam sábios ou ignaros, os homens são sempre partes da natureza. Sob a condução da razão ou do desejo, tudo o que os homens fazem está em conformidade com as leis e regras da natureza, em função do direito natural (TP, Capítulo II, §5).

No estado natural pensado por Espinosa, cada um é juiz de si mesmo enquanto é capaz de se defender das opressões dos outros, mas como o esforço individual de defender a si mesmo se torna ineficiente sempre que o direito natural do homem for determinado pela potência de cada um, esse direito será inexistente na realidade, tendo eventualmente apenas uma existência teórica, uma vez que não haverá uma forma segura de cada um se conservar. Ademais,

${ }^{10}$ Na Ética, Parte III, Proposição IX, Escólio, Espinosa afirma que o desejo é o apetite de que se tem consciência.

Educ. e Filos., Uberlândia, v. 22, n. 43, p. 63-87, jan./jun. 2008 
afirma Espinosa, quanto mais razões um homem tem para temer, tanto menor será sua potência ou seu direito. Sem, por outro lado, uma cooperação mútua (mutuo auxilio) os homens jamais poderão cultivar sua alma e bem viver. Desse modo, o filósofo conclui que:

[...] o direito natural, relativamente ao próprio gênero humano, dificilmente pode ser concebido, senão quando os homens têm direitos comuns, terra que podem habitar e cultivar em comum, quando podem vigiar a manutenção do seu poder, proteger-se, combater qualquer violência e viver conforme um apetite comum (TP, Capítulo II, \$15).

No terceiro capítulo do $T P$, parágrafo 2 , tendo por base o que explanara no parágrafo quinze do segundo capítulo, Espinosa afirma que o direito do império ou do poder público (ou seja, o direito civil) não é senão o direito natural, não enquanto é determinado por cada indivíduo, mas enquanto é determinado pela multidão que age como uma só alma. Se o império concedesse a todos o direito de viver cada um a seu modo, o império seria destruído e voltar-se-ia ao estado natural. Portanto, o império não deve conceder esse direito a ninguém, de modo que o direito natural que determina que cada indivíduo viva sob seu modo próprio cessa necessariamente no estado civil. Ressalva Espinosa, porém, que ele se refere a uma concessão legal, pois no estado civil ninguém deixa de ter o seu direito natural (seria naturalmente impossível que deixassem de ter), de modo que tanto no estado civil, quanto no estado natural, o homem age em conformidade com as leis da sua natureza e guarda seus interesses.

A diferença entre o estado civil e o estado natural é que, no primeiro, todos os homens temem os mesmos males, há para todos uma mesma forma de segurança e, em sua totalidade, os homens têm um mesmo modo de viver (o que não destrói a faculdade de julgar de cada indivíduo).

Portanto, conforme salienta Marilena Chauí (2003b, p. 251), para Espinosa, 
[...] o advento da vida social e política não é o advento da 'boa razão' humana que dominará as paixões, condenará os vícios, eliminará os conflitos e estabelecerá definitivamente a paz e a concórdia entre os homens. [...] A cidade é habitada por um conflito entre a potência coletiva e a potência individual que, como todo conflito, segundo a Ética, só pode ser resolvido se uma das partes tiver poder para satisfazer e limitar a outra, pois uma paixão nunca é vencida por uma razão ou uma idéia verdadeira, mas por uma outra paixão contrária e mais forte do que ela.

\section{A continuação da guerra: Foucault contra Hobbes}

Michel Foucault é incisivo no início da redação do "Resumo do Curso" Em Defesa da Sociedade, ministrado por ele no College de France em $1976^{11}$ :

Para realizar a análise concreta das relações de poder, deve-se abandonar o modelo jurídico da soberania. Este, de fato, pressupõe o indivíduo como sujeito de direitos naturais ou de poderes primitivos; propõe-se o objetivo de explicar a gênese ideal do Estado; enfim, faz da lei a manifestação fundamental do poder. Dever-se-ia tentar estudar o poder não a partir de termos primitivos da relação, mas a partir da própria relação na medida em que ela determina os elementos sobre os quais incide: em vez de perguntar a sujeitos ideais o que puderam ceder de si mesmos ou de seus poderes para deixar-se sujeitar, deve-se investigar como as relações de sujeição podem fabricar sujeitos (FOUCAULT, 1999a, p. 319) ${ }^{12}$.

A proposição do curso de Foucault, como se nota, coloca-se de

${ }^{11} \mathrm{O}$ curso "Em Defesa da Sociedade" ou, como também é citado, "É Preciso Defender a Sociedade", foi realizado no primeiro semestre de 1976 e localizase historicamente entre a publicação de Vigiar e Punir (de fevereiro de 1975) e A Vontade de Saber (outubro de 1976). Cf. "Situação do Curso", texto redigido por Alessandro Fontana e Mauro Bertani (FOUCAULT, 1999a, p. 327 - 351).

${ }^{12} \mathrm{O}$ "Resumo" deste curso de Foucault possui outra tradução, de Andréa Daher, que pode ser encontrada no volume Resumo dos Cursos do Collège de France (1970-1982), de Michel Foucault (1997).

Educ. e Filos., Uberlândia, v. 22, n. 43, p. 63-87, jan./jun. 2008 
uma forma imperativa e determinante: é preciso, se se quiser realizar a análise concreta das relações de poder no interior da sociedade, abandonar o esquema jurídico que pretende explicar a origem ideal do Estado fazendo da lei a manifestação que fundamenta o poder, pressupondo os indivíduos como sujeitos de um direito natural. Insistindo nisso, Foucault - de maneira decisiva - propõe paralelamente uma análise do poder fora do que chama de modelo "contrato-opressão" e dentro do modelo "guerrarepressão".

Ao estabelecer sua crítica ao modelo jurídico no início do citado "Resumo", Foucault deixa claro, para o leitor ou ouvinte de seu curso, que seu alvo filosófico-político é o pensador inglês Thomas Hobbes.

Foucault ocupa boa parte de uma de suas aulas dedicando-se exclusivamente à crítica e desmembramento do pensamento político de Hobbes $^{13}$, trata-se da aula de 4 de fevereiro, precedida pela aula de 28 de janeiro que aborda, por sua vez, o discurso histórico, a história como operador de poder, a idéia de contrahistória, a mudança de função da memória, a emergência da consciência da ruptura, as funções políticas do discurso histórico e, finalmente, o "Racismo de Estado". É justamente, pois, prometendo tratar da história do discurso das raças nas próximas aulas que Foucault encerra o dia letivo de 28 de janeiro e, após alguns esclarecimentos sobre a questão do racismo no início da aula de 4 de fevereiro, parte para uma reflexão sobre o pensamento político de Hobbes, afirmando que "gostaria de tentar ver como a

${ }^{13}$ Foucault propõe, no início do curso, uma alteração profunda do esquema hobbesiano do Leviatã (corpo = súditos, cabeça = soberania). Ao invés de estudar a cabeça, ele pretende estudar os "corpos periféricos e múltiplos" que foram constituídos como súditos (FOUCAULT, 1999a, p. 34). Pouco adiante Foucault é mais objetivo: "Em suma, é preciso desvencilhar-se do modelo do Leviatã, desse modelo de um homem artificial, a um só tempo autômato, fabricado e unitário igualmente, que envolveria todos os indivíduos reais, e cujo corpo seriam os cidadãos, mas cuja alma seria a soberania. É preciso estudar o poder fora do modelo do Leviatã, fora do campo delimitado pela soberania jurídica e pela instituição do Estado [...] (FOUCAULT, 1999a, p. 40)".

Educ. e Filos., Uberlândia, v. 22, n. 43, p. 63-87, jan./jun. 2008. 
guerra começou a aparecer como analisador das relações de poder, no fim do século XVI e no início do século XVII (FOUCAULT, $1999 a$, p. 102 $)^{14 \prime \prime}$.

Foucault inicia sua consideração do pensamento de Hobbes afirmando que esse autor é tomado como aquele que pôs a relação de guerra no fundamento das relações de poder, defendendo que no fundo da ordem, da lei e da paz há uma guerra total (de todos os homens contra todos os homens). Tal guerra, no dizer de Foucault, não é apenas o que promove o princípio do Estado, mas está presente também após o seu estabelecimento, ameaçando-o em sua ordem e sua paz. Foucault recupera, a esta altura de sua exposição, o que chama de "os três exemplos dessa guerra permanente": os cuidados dos súditos em um Estado Civil, as tribos americanas e a relação entre Estados na Europa ${ }^{15}$. Posto isso, Foucault coloca duas questões: (a) qual é essa guerra preliminar e posterior ao Estado de que Hobbes trata? e (b) como essa guerra engendra o Estado?

Foucault inicia sua resposta apontando que a guerra hobbesiana nasce da igualdade e nela se desenvolve, não se tratando de uma guerra que tenha como ponto de partida as

${ }^{14}$ Conquanto Hobbes seja recuperado por Foucault diversas vezes durante o curso, o tratamento objetivo do pensamento político do filósofo inglês dá-se da página 102 à página 115 desta edição de Em Defesa da Sociedade.

${ }^{15}$ Foucault alude aqui às três formas de expressão da guerra de todos contra todos no pensamento de Hobbes: a primeira forma (que envolve os cuidados dos súditos mesmo em um Estado Civil) é aquela em que o filósofo inglês pede a alguém que viva sob um Estado Civil lembrar-se de que, mesmo sob a proteção do soberano, ele toma o cuidado de, ao viajar, armar-se e ir-se bem acompanhado, ou ainda que esteja em casa, fecha bem seus cofres, embora saiba que existem leis e funcionários armados prontificados para vingar qualquer lesão que lhe seja auferida por outrem; a segunda (que alude a algumas tribos americanas) é aquela em que - conforme as palavras de Hobbes - há lugares em que indivíduos vivem sem qualquer espécie de governo; e a terceira forma (que pode ser tomada nos exemplos das relações entre os Estados) é aquela em que há uma constante rivalidade entre reis. Tais considerações feitas por Hobbes e recuperadas por Foucault estão no final do Capítulo XIII, Parte I do Leviatã.

Educ. e Filos., Uberlândia, v. 22, n. 43, p. 63-87, jan./jun. 2008 
diferenças entre os homens, pois, segundo Hobbes, se houvesse diferenças naturais agudas entre os homens, a guerra seria brecada, uma vez que seu resultado já estaria dado de antemão, quando os mais fracos aceitariam a submissão aos mais fortes, a fim de evitar a morte certa na guerra. A diferença, em Hobbes, conforme salienta Foucault, pacifica: é da igualdade que surge a guerra ${ }^{16}$.

De sua análise de Hobbes, Foucault extrai a conclusão de que a guerra total (pertencente ao estado natural hobbesiano) não é brutal e sanguinária como aparenta, pois é determinada por três séries de elementos: representações calculadas ("eu represento para mim a força do outro, represento-me que o outro representa minha força"), manifestações enfáticas da vontade ("demonstra-se que se quer a guerra, mostra-se que não se renuncia à guerra") e táticas de dominação entrecruzadas ("receio tanto fazer a guerra que só ficarei tranqüilo se você recear a guerra pelo menos tanto quanto eu - e mesmo, na medida do possível, um pouco mais") (FOUCAULT, 1999a, p. 105). Assim, segundo Foucault, não há uma guerra real, nem cadáveres nesta proposta de Hobbes, mas uma "diplomacia infinita de rivalidades" que são, por natureza, igualitárias.

Tendo evidenciado que esse estado de natureza não é, em verdade, uma guerra, mas jogos de representação, Foucault segue então para sua segunda questão: como isso (que, de fato, não é guerra) engendrará o Estado em Hobbes?

A resposta de Hobbes, segundo Foucault, tem em vista a divisão

${ }^{16}$ A consideração da igualdade entre os homens é feita por Hobbes no princípio do Capítulo XIII, Parte I do Leviatã. É, pois, a essa passagem do texto do Leviatã que Foucault se refere. Vale ressaltar que Foucault, ainda que de forma rápida, ressalva que Hobbes não incorre no absurdo de afirmar que os homens são meramente iguais. Hobbes admite que haja diferenças entre os homens, mas essas são de tal natureza que podem ser compensadas. Por exemplo: alguém que seja mais forte pode vencer outro que seja mais fraco do que ele através da luta física, mas o mais fraco fisicamente também pode, por sua vez, vencer o mais forte por secreta maquinação intelectual. Portanto, para Hobbes, mesmo as diferenças conduzem à igualdade entre os homens, o que torna a guerra iminente.

Educ. e Filos., Uberlândia, v. 22, n. 43, p. 63-87, jan./jun. 2008. 
da soberania em duas formas: o Estado Instituído e o Estado Adquirido $^{17}$. Na primeira forma de Estado, os cidadãos cedem o direito de que alguém ou uma assembléia os represente integralmente. O soberano não terá, segundo a leitura que Foucault faz de Hobbes, parte dos poderes ou dos direitos dos súditos, mas estará no lugar deles, representando sua totalidade. O Estado Instituído se compõe, pois, do jogo de vontade, do pacto e da representação. O Estado Adquirido, outra forma de constituição da república é - também na visão de Foucault - apenas aparentemente distinto do Estado Instituído. Supondo desta vez uma guerra real, Foucault apresenta o Estado Adquirido hobbesiano como aquele em que, após uma guerra, um dos estados vence o outro. Nesse caso, ou os vencidos são mortos ou então se mantêm vivos. Em caso de morte de todos os súditos não haverá, de fato, soberania, mas no caso da sobrevivência de alguns deles, nem por isso haverá dominação, mas ainda existirá soberania, uma vez que os vencidos passem a obedecer ao regime estabelecido pelos vencedores; dessa forma, seus vencedores serão, portanto, seus soberanos.

Há, para Foucault, mais uma forma de soberania em Hobbes, a saber, aquela que pode ser tomada como similar à relação entre pais e filhos: o filho obedece à mãe, pois é ela quem lhe conserva a vida; de acordo com Foucault, o mesmo se passa na relação política entre vencedores e vencidos: o vencido passa a obedecer ao vencedor, pois este lhe garante a vida ${ }^{18}$.

Nas palavras de Foucault, a soberania hobbesiana é constituída a partir de uma forma radical de vontade que se vincula ao medo. Essa soberania é formada sempre a partir dos vencidos, dos filhos,

\footnotetext{
${ }^{17}$ Hobbes trata do Estado por instituição e do Estado por aquisição nos capítulos XVIII, XIX e XX do Leviatã, respectivamente. Tais capítulos são antecedidos pelo capítulo XVII, que apresenta as causas, a geração e a definição de um Estado. É este capítulo XVII que inicia a Parte II do Leviatã.

${ }^{18}$ Tais considerações, Hobbes as desenvolve ainda no Capítulo XX da Parte II do Leviatã. A edição de Em Defesa da Sociedade (1999) aqui utilizada remete também à obra de Hobbes Sobre o Cidadão (De Cive), Parte II, Capítulo IX.
} 
dos súditos, ou seja, é formada por baixo, não por cima. Não importa se o Estado é instituído ou conquistado; segundo o pensador contemporâneo francês, em ambos os casos, os mecanismos são os mesmos, o que evidencia que Hobbes quis eliminar a guerra como realidade histórica e não é o teórico das relações entre guerra e poder político, a despeito de como ele é tomado pela maioria de seus leitores. O discurso de Hobbes é um "não" à guerra.

Para Foucault, portanto, o adversário de Hobbes não é uma teoria contrária à dele. O adversário hobbesiano é aquilo que havia em seu tempo, um vis-à-vis estratégico que Hobbes queria eliminar, isto é, ele queria fazer o saber histórico das guerras funcionar na luta política. Hobbes quis, na leitura de Foucault, eliminar a conquista. O problema da conquista resolver-se-ia com a noção de guerra total (no início) e por uma certa "vontade de Estado" dos vencidos. $\mathrm{O}$ inimigo de Hobbes é a guerra civil que cada vez mais ameaçava o Estado (inglês). Tal discurso hobbesiano teria, então, surgido na Inglaterra com a conjunção de dois fenômenos: a disputa precoce entre burguesia e monarquia na Inglaterra e a aristocracia; além disso, passaria a haver também a consciência do fato histórico da antiga clivagem da conquista ${ }^{19}$.

Na seqüência, Foucault passa a tratar justamente desse adversário de Hobbes, reconstituindo a história da conquista. Para o autor de Vigiar e Punir, Hobbes queria, ao eliminar a guerra, eliminar o problema da conquista inglesa; em prazo mais longo -

${ }^{19}$ Parece ser o caso, a fim de deixar mais evidente a sugestão de Foucault, apresentar um paralelo cronológico entre a vida de Hobbes e os acontecimentos históricos que marcaram o século XVII na Inglaterra. Hobbes nasceu em 1588, no fim do período regido pela Dinastia Tudor, quinze anos antes da morte de Elizabeth I que deu início ao período que se formou sob o comando da Dinastia Stuart (governado por James I e Charles I). A obra De Cive foi publicada no ano em que estourou a Guerra Civil Inglesa (1642). Dois anos antes de publicar o Leviatã, em 1651, havia sido dado fim à guerra e início ao período republicano, governado pelo comandante vitorioso da guerra, Oliver Cromwell, que - em 1653 - tornar-se-ia Lord Protector. Hobbes ainda presenciou a Restauração dos Stuart, mas faleceu nove anos antes de assistir à chegada de Guilherme, que consistiu na chamada Revolução Gloriosa.

Educ. e Filos., Uberlândia, v. 22, n. 43, p. 63-87, jan./jun. 2008. 
acrescenta ele - Hobbes queria evitar o historicismo político, isto é, uma espécie de discurso que consiste em afirmar que as relações de poder não estão na perspectiva da soberania e dos direitos, mas se fortalecem como dominação. Era este historicismo político (o saber e o discurso efetivamente em vigor nas lutas políticas do XVII) que Hobbes queria, finalmente, eliminar.

\section{A continuação do direito natural e a continuação da guerra}

Dois autores se opõem ao pensamento jurídico de Hobbes em seus respectivos contextos históricos, visando, portanto, a fins distintos e sob esquemas próprios de investigação da realidade. Espinosa propõe a negação das definições de direito natural e direito civil em Hobbes (na "Carta n ${ }^{\circ} 50^{\prime}$ " de 2 de junho de 1674) e Foucault propõe o abandono do modelo de análise das relações de poder expresso no Leviatã (na aula de 4 de fevereiro de 1976).

Espinosa, identificando direito e lei e entendendo o primeiro como potência, afirma que o direito civil deve vigorar a fim de tornar concreta ao homem a plena realização de sua potência ou direito natural. Ele compreende que, na vida política, o homem não é, de forma alguma, conduzido pela razão, mas sim pelo desejo cego e que, desta forma, mesmo após a constituição do Estado Civil, haverá os mesmos conflitos que havia antes (em um Estado de Natureza), mas agora este direito ou potência natural não ficará apenas na teoria, tendo uma existência real ${ }^{20}$, determinada não só pelo que cada indivíduo pode isoladamente, mas pelo que pode toda a multidão. Em Espinosa, a relação de causalidade (dando-se de forma discrepante daquela pela qual se dá em Hobbes) define uma potência que não existe senão em ato, ou seja, que só existe enquanto se exerce. $\mathrm{O}$ direito natural espinosano, muito oposto àquele que Foucault critica em Hobbes, não é constituído por representações, sinais ou expressões, mas é exercido na vida real

${ }^{20}$ Na Ética, Parte II, Definição 6 diz Espinosa: "Por realidade e por perfeição entendo a mesma coisa". Há uma justificativa para esta definição, presente no "Prefácio" à Parte IV da mesma obra. 
de homens reais, que fazem parte da natureza e que, como tais, estão naturalmente submetidos às paixões.

O que Hobbes queria eliminar, na leitura de Foucault, parece convir exatamente com aquilo que Espinosa fez mister evidenciar, emergir. Espinosa mostrou a impossibilidade de os súditos transferirem seus direitos a um soberano e mostrou também como esta transferência seria desnecessária ${ }^{21}$. Esse rompimento radical com Hobbes permite a Espinosa pensar a vida política na base de um conflito real permanente, que eleve o homem à sua máxima potência possível de agir e pensar, conquanto também esteja permeado de paixões tristes, as quais - ao contrário das paixões alegres - têm no homem uma causa parcial ou inadequada que o conduz de uma perfeição maior a outra menor.

Espinosa, dado seu contexto histórico e através de seu esquema próprio de investigação da realidade - que procede através das relações de causalidade -, é levado a afirmar, diferentemente de Foucault, que a melhor forma de regime político é a democracia, pois ela consiste no mais natural dos regimes por permitir que, sob a maior potência possível, esse conflito se realize.

${ }^{21} \mathrm{O}$ "Capítulo XVII" do TTP tem, no início de seu título, a seguinte afirmação: "Onde se mostra que é impossível e desnecessário a alguém transferir os seus direitos para o poder soberano [...]". Uma vez que a reconstrução da argumentação espinosana em torno dessa tese e sua explicação tomariam muito espaço, este estudo se limita a transcrever parte essencial do texto de Espinosa sobre este assunto: "Ninguém, com efeito, pode alguma vez transferir para outrem o seu poder e, conseqüentemente, o seu direito, ao ponto de renunciar a ser um homem. Nem tão-pouco haverá soberano que possa fazer tudo a sua vontade: debalde ele ordenaria a um súdito que odiasse o seu benfeitor ou que amasse quem lhe tivesse feito mal, que não se ofendesse com injúrias que não desejasse libertar-se do medo, e muitas outras coisas semelhantes que decorrem necessariamente das leis da natureza humana. Julgo que a própria experiência ensina isto de forma bastante clara: jamais os homens renunciaram ao seu próprio direito e transferiram para outrem o seu poder em termos de tal maneira definitivos que aqueles que os receberam das suas mãos o direito e o poder deixassem de os temer e que o Estado não estivesse mais ameaçado pelos cidadãos, ainda que privados do seu direito, do que pelos inimigos (TTP, Capítulo XVII)".

Educ. e Filos., Uberlândia, v. 22, n. 43, p. 63-87, jan./jun. 2008. 
Já Foucault, estando por sua vez adiantado trezentos anos na história e sob outro esquema investigativo da realidade (que não é o princípio de causalidade) não rende homenagem à democracia, mas à guerra, saindo completamente do esquema jurídico das filosofias do século XVII. Todavia, há uma aproximação fundamental entre os dois que - revelada pela crítica de ambos a Hobbes - mostra-se como a preferência pelo esquema que analisa as relações de poder por um viés contrário ao do contratorepressão. Espinosa defende uma sociedade (civitas) que aspira à paz e à segurança da multidão, mas que, conforme argumenta Foucault, está permeada e composta por conflitos reais.

\section{O papel das universidades em Espinosa e Foucault}

É muito conhecida a recusa de Espinosa ao convite para lecionar em Heidelberg. Procurado por carta pelo conselheiro do Eleitor Palatino, chamado Ludwig Fabritius, que lhe oferecia a cátedra na Academia em que lecionava, Espinosa nega a oferta mesmo consciente de que lhe fora garantida uma liberdade de filosofar. A negação de Espinosa tem duas razões: (a) o fato de que os cuidados exigidos para a instrução da juventude o impediriam de continuar fazendo progressões na filosofia e (b) o fato de não saber ao certo em quais limites estaria compreendida a liberdade de filosofar que lhe fora concedida (ESPINOSA, "Carta $\left.48^{\prime \prime}\right)^{22}$.

Menos conhecida do público do que essa recusa é a passagem em que Espinosa faz algumas considerações acerca das academias fundadas às custas da república:

As Academias [Academiae] fundadas às custas [sumptibus] da república [reipublicae] são instituídas menos para cultivar o espírito [ad ingenia colenda] do que para o constranger [ad eadem coercenda].

\footnotetext{
${ }^{22}$ Uma tradução portuguesa desta carta (feita por José Perez) pode ser lida em PEREZ (2001, p. 175-179).
} 
Todavia, em uma república livre [in libera Republica], a melhor forma de se cultivar [excolentur] as ciências e as artes é conceder a licença [petenti concedatur] a cada um para ensinar publicamente [docere publice] às suas custas [suis sumptibus] e com o perigo da sua reputação [suaeque famae periculo] (TP, "Capítulo VIII", § 49) ${ }^{23}$.

Esse fragmento do Tratado Político é, porém, rapidamente encerrado, afirmando o autor que reserva tais questões e outras semelhantes para outro lugar, uma vez que - naquele espaço - ele deseja apenas tratar do que pertence ao Estado Aristocrático.

De fato, o fragmento transcrito acima aparenta estar fora de contexto, pois Espinosa, no parágrafo anterior, estava a tratar da prestação de juramento determinada pela lei e logo em seguida passou a se referir às academias. Outra dificuldade desse excerto é sua abrupta interrupção, com a promessa de maiores esclarecimentos posteriores (os quais nunca chegaram a ser feitos ${ }^{24}$ ).

Luis Machado de Abreu (1993) chegou a escrever sobre esse fragmento. Em sua leitura, ele afirma que as instituições estatais são apresentadas por Espinosa como instrumentos de controle e

${ }^{23} \mathrm{O}$ exagero de referências ao texto espinosano original, em língua latina, apresentado nesta citação não se faz sem razão. As diversas traduções do Tratado Político de que o público brasileiro dispõe (já citadas) deixam novamente a desejar neste particular ao apresentarem, entre outros, os seguintes problemas: 1. O termo "Republica" é ora traduzido por "Estado", ora por "República" (nas traduções de Manuel de Castro e Norberto de Paula Lima, o termo - que aparece duas vezes neste trecho - é traduzido por "Estado" na primeira incidência e por "República" na segunda incidência, estando ambas iniciadas por maiúsculas, enquanto o texto original as cita em minúsculas); 2. O advérbio "publice", referente ao verbo "docere" ("ensinar publicamente"), é ocultado ou esquecido nas traduções de Manuel de Castro e Norberto de Paula Lima; 3. A versão de José Perez traduz a primeira incidência de "sumptibus" por "às expensas" e a segunda incidência da mesma palavra por "por conta", deixando - neste segundo caso - de reforçar o caráter propriamente financeiro da palavra (que pretende designar "gastos", "custos"). Parece, pois, pertinente traduzir as duas incidências por "às custas" (como foi feito neste estudo) ou - como prefere José Perez - por "às expensas".

${ }^{24} \mathrm{O}$ Tratado Político ficou inacabado nas primeiras linhas do décimo primeiro capítulo, em função da morte de Espinosa.

Educ. e Filos., Uberlândia, v. 22, n. 43, p. 63-87, jan./jun. 2008. 
de dominação. "O pecado original reside na subordinação ao poder que delas dispõe através de mecanismos de financiamento (p. 108)". A forma espinosana proposta para o ensino está, segundo ele, baseado na iniciativa privada com sansão do Estado e no jogo da opinião pública. $\mathrm{O}$ modo pelo qual essa iniciativa privada se realizaria, embora não tenha sido expresso por Espinosa, estaria talvez concebido em um ensino centrado no professor. Para reforçar essa idéia, Abreu cita uma passagem importante do TTP,a saber:

O estado mais violento será, portanto, aquele em que se nega a cada um a liberdade de dizer e ensinar o que pensa, e será, ao contrário, moderado, o estado em que se concede a todos essa mesma liberdade ("Capítulo XX") $)^{25}$.

Se as academias fundadas às custas da república são instituídas mais para constranger o espírito do que para cultivá-los e a condição para que as ciências e as artes sejam cultivadas da melhor forma é conceder a qualquer um a licença para ensinar por sua custa e com o perigo de sua reputação (o que só aconteceria em uma república livre), parece - de fato - inegável que Espinosa esteja estabelecendo uma crítica ao cerceamento da liberdade engendrado pelos estados; trata-se, portanto, do mesmo cerceamento que consistiu em uma das razões que o levou a negar a cátedra em Heidelberg. O ensino deve se dar, em uma república livre, sem a tutela e sem nenhum custeio do estado, ficando a cargo do professor o financiamento de seu ensino e a responsabilidade de suas afirmações.

Passando agora às idéias de Foucault, é preciso recorrer à sua aula de 25 de fevereiro de 1976, em que - após uma série de considerações - o autor aborda a distinção entre a "história das ciências" e a "genealogia dos saberes" ${ }^{26}$. Segundo ele, a primeira

${ }^{25}$ Nessa citação, "estado" está traduzindo "imperium".

${ }^{26} \mathrm{O}$ papel desenvolvido pelas universidades é abordado por Foucault, objetivamente, na página 219 de Em Defesa da Sociedade. Todavia, todo o contexto que o leva a tratar da universidade se estende da página 213 a 218. 
está no eixo conhecimento-verdade e a segunda, no eixo discursopoder. A tarefa da genealogia seria justamente desvelar a época do iluminismo, evidenciando a existência de um múltiplo embate de saberes, uns contra os outros, e não um consensual progresso da razão.

Tomando como eixo o saber técnico produzido pelo século XVIII, Foucault afirma que ele funcionou em meio aos múltiplos saberes e que, conforme houve um aumento de demanda econômica sobre eles, os saberes menores passaram a ser envolvidos pelos maiores. Nessas lutas entre saberes, o Estado interveio direta ou indiretamente sob quatro procedimentos: (a) eliminação e desqualificação dos saberes pequenos, inúteis e economicamente dispendiosos; (b) normalização dos saberes entre si; (c) classificação hierárquica desses saberes a fim de encaixá-los uns nos outros e (d) centralização piramidal com vistas a controlar os saberes. Essas quatro operações atuam sobre o poder disciplinar. Correspondente a esse movimento de organização dos saberes, Foucault ainda ressalta que existe toda uma série de práticas, empreendimentos e instituições; a Enciclopédia seria um deles.

Nesse sentido, ao invés de um progresso harmonioso da razão, houve - para Foucault - um disciplinamento dos saberes polimorfos e heterogêneos (FOUCAULT, 1999a, p. 218).

Compreendendo isso, o filósofo francês afirma que é possível entender também, entre outras questões, o aparecimento da universidade (não no sentido estrito, uma vez que ela já desempenhava seu papel e função muito antes). O que, porém, é digno de atenção, é que a partir do fim do século XVIII e início do século $\mathrm{XIX}^{27}$, a universidade aparece como um grande aparelho de uniformização dos saberes, com suas diferentes categorias e seus diferentes prolongamentos.

Segundo Foucault, a universidade tem, acima de tudo, a função de seleção dos saberes, que ela exerce com uma espécie de

\footnotetext{
${ }^{27}$ Foucault registra, como parte desta época, o nascimento da universidade napoleônica.
}

Educ. e Filos., Uberlândia, v. 22, n. 43, p. 63-87, jan./jun. 2008. 
monopólio e direito. Isso faz com que o saber que nela não nasceu ou que nela não se formou, seja ou excluído de imediato, ou desclassificado a priori. Nesse período, desaparece o cientista amador.

O papel de seleção de saberes, produzido pela universidade, desdobra-se também na função de distribuição do escalonamento, da qualidade e da quantidade de saberes nos mais diferentes níveis. Foucault reforça: tal é o papel do ensino com todas as barreiras existentes entre os diferentes escalões do aparelho universitário; é um papel de seleção e de homogeneização desses saberes, dada pela constituição de certa forma de comunidades científicas que possuem estatutos reconhecidos. Trata-se da organização de um consenso em torno dos saberes que visa à centralização, mediante o caráter direto ou indireto de aparelhos de Estado. Foucault localiza o aparecimento da universidade, finalmente, a partir do momento em que os saberes foram disciplinados.

É mister relembrar que, neste curso de 1976, Foucault parte da distinção entre "história das ciências" e "genealogia dos saberes"; tomando uma perspectiva genealógica, ele desmantela a época das Luzes, revelando que o suposto "progresso da razão" operou em meio a uma esquecida luta de múltiplos saberes entre si. O desenvolvimento dos saberes técnicos foi, por exemplo, desenvolvido mediante quatro procedimentos de organização de saberes que, uma vez compreendidos, permitem que se entenda a origem e o papel da universidade na transição do século XVIII ao século XIX.

Já que a história das ciências se encontra no eixo conhecimentoverdade, convém consultar o conjunto de conferências de Foucault realizado no Brasil em 1973, intitulado A Verdade e as Formas Jurídicas $^{28}$.

Na quinta conferência deste curso, que teve posteriormente uma publicação em livro, o filósofo tece o seguinte comentário:

${ }^{28}$ A Verdade e as Formas Jurídicas, conquanto possua a estrutura de um curso, está distribuída em cinco conferências. Este curso antecede em três anos ao curso Em Defesa da Sociedade, ministrado na França. 
O sistema escolar é também inteiramente baseado em uma espécie de poder judiciário. A todo momento se pune e se recompensa, se avalia, se classifica, se diz quem é o melhor, quem é o pior. [...] Este sistema parece evidente, mas, se refletimos, vemos que a evidência se dissolve; se lemos Nietzsche vemos que se pode conceber um sistema de transmissão do saber que não esteja no interior de um aparelho de sistema de poder judiciário, político, econômico, etc. (FOUCAULT, 1999b, p. 120-121).

Conquanto estas ponderações de Foucault estejam visivelmente mais próximas do assunto tratado em Vigiar e Punir, redigido em 1975, elas parecem extremamente esclarecedoras para o tema aqui tratado; principalmente quando, ao fim da referida citação, o filósofo recorre a Nietzsche para sugerir a desvinculação do ensino em relação ao edifício jurídico, político e econômico.

Essa defesa da desvinculação do ensino do edifício político, sustentada por Foucault a partir de Nietzsche, em muito se aproxima da defesa de Espinosa por um ensino que cultive e não constranja os espíritos. Se, por outro lado, está correta a interpretação de Abreu (1993) alegando que Espinosa tem em vista questionar o controle e a dominação das universidades, há uma aproximação muito intensa entre os dois filósofos aqui tomados.

A república livre (libera republica) de Espinosa, aquela que garante a plena realização do direito natural como potência de agir e pensar dos indivíduos (direito, a propósito, continuado mesmo depois da instituição do estado civil), não conterá as censuras e os controles do Estado, nem estará cumprindo um papel de constrangimento de espírito, mas se preocupará com seu cultivo.

Todavia, digna de nota é a constatação de que Espinosa se refere à universidade de seu tempo, portanto, à universidade existente no século XVII ${ }^{29}$. Foucault, por outro lado, ao apontar o

${ }^{29}$ Segundo nota de Manuel de Castro à tradução do Tratado Político (ESPINOSA, 1979 , p. 356, nota $\left.n^{\circ} 19\right)$, Espinosa tinha como referência a Universidade de Leyden, "onde o ensino filosófico e teológico tinha principalmente como finalidade estabelecer solidamente no espírito dos estudantes os dogmas da igreja calvinista".

Educ. e Filos., Uberlândia, v. 22, n. 43, p. 63-87, jan./jun. 2008. 
caráter de seleção dos saberes da universidade, refere-se àquela forma de universidade que passou a existir desde o final do século XVIII, embora indique um modelo de universidade prévio que já existia bem antes. Há, portanto, que se respeitar, nesta aproximação entre Espinosa e Foucault, seus respectivos contextos históricos. Todavia, percebe-se que Espinosa, sob sua forma singular de investigação do universo político (muito distinta daquela empregada por Foucault séculos depois), antecipa em boa medida as conclusões retiradas da análise foucaultiana de Hobbes e aponta - ainda que de forma pouco elaborada - para aquilo que será objeto de atenção em Foucault, isto é, o papel de seleção de saberes.

\section{Conclusão}

Aproximar dois filósofos como Espinosa e Foucault não é uma tarefa fácil, sobretudo considerando a especificidade de seus tempos históricos e seus métodos de investigação. Todavia, os indícios de que ambos estão bem próximos são assaz interessantes: ambos criticam a filosofia política de Hobbes e se centram na crítica aos seus conceitos de direito natural e direito civil; ademais, ambos criticam - de forma muito similar - as universidades e, ainda que estejam se referindo a momentos históricos diferentes da universidade, atacam-lhe pontos extremamente coincidentes: seu papel de "constrangimento do espírito" (Espinosa) e de "seleção e homogeneização de saberes" (Foucault).

Sem dúvida alguma, a análise de Espinosa não substitui a análise de Foucault. Foucault, além de desenvolver a questão bem mais do que Espinosa (que por falta de tempo de vida não pode levar a cabo suas análises), tem por base um conjunto de reflexões políticas próprias ao século XX. Embora o pensamento de Espinosa também seja plenamente capaz de oferecer instrumentos que possibilitem a compreensão do tempo atual, em hipótese alguma como foi expresso - uma análise substitui a outra.

Questões invariavelmente ficam à espera de tratamento ao cabo deste texto, uma vez que ele se limitou a abordar o pensamento de Espinosa e de Foucault que foram expressos em poucas partes de

Educ. e Filos., Uberlândia, v. 22, n. 43, p. 63-87, jan./jun. 2008 
suas obras, deixando de incluir apontamentos importantes - que ambos fazem sobre o mesmo assunto - em outras obras. Isso foi feito com vistas a delimitar a problemática deste estudo que poderia eventualmente perder-se em considerações excessivamente vagas.

Caberia, futuramente, que fosse produzida uma leitura mais precisa de Hobbes a fim de confrontar o texto desse filósofo com aquilo que os dois autores aqui tratados dele compreendem. Além disso, haveria de ser pontuado qual é exatamente o lugar da educação no pensamento de Espinosa, para que fosse possível entender com precisão como este filósofo concebia, de fato, o ensino. No tocante a Foucault, caberia talvez uma inserção mais aprofundada em outras obras, como Vigiar e Punir e A Vontade de Saber, além da leitura de alguns fragmentos dispersos em que o autor mencione a questão da universidade.

Por outro lado, este estudo cumpre a tarefa de aumentar o conhecimento já existente acerca da relação entre filósofos modernos e contemporâneos, mostrando suas discordâncias e aproximações. Finalmente, também acrescenta algo mais sobre a tentativa de compreensão, pela filosofia da educação, da natureza e função das universidades.

\section{Referências:}

ABREU, L. Spinoza - A Utopia da Razão. Lisboa: Vega, 1993.

CHAUÍ, M. A nervura do real. São Paulo: Companhia das letras, 1999.

CHAUÍ, M. Direito Natural e Direito Civil em Hobbes e Espinosa. In: CHAUÍ, M. Política em Espinosa. São Paulo: Companhia das Letras, 2003a, p. 289-314.

Direito é Potência - Experiência e Geometria no "Tratado Político". In: CHAUÍ, M. Política em Espinosa. São Paulo: Companhia das Letras, 2003b, p. 197-264.

DELEUZE, G. Espinosa e os signos. Tradução de Abílio Ferreira. Porto-Portugal: Rês, s/d.

Educ. e Filos., Uberlândia, v. 22, n. 43, p. 63-87, jan./jun. 2008. 
ESPINOSA, B. Os Pensadores. São Paulo: Abril Cultural, 1979. Vários tradutores.

Tratado Teológico-Político. Notas, Tradução e Introdução de D. P. Aurélio. Lisboa: Imprensa Nacional, 1988. (Série Estudos Gerais).

FOUCAULT, M. Surveiller et Punir. Paris: Gallimard, 1975. Resumo dos Cursos do Collège de France (1970-1982). (Tradução de Andréa Daher). Rio de Janeiro: Zahar, 1997. Em Defesa da Sociedade. São Paulo: Martins Fontes, 1999a. Tradução de Maria Ermantina Galvão.

A Verdade e as Formas Jurídicas. Tradução de Roberto Machado e Eduardo Jardim Moraes. Rio de Janeiro: Nau, 1999b.

HOBBES, T. Leviathan. Harmondsworth: Penguin Books, 1968. Edited by McPherson.

NEGRI, A. A Anomalia Selvagem - Poder e Potência em Spinoza. Tradução de Raquel Ramalhete. Rio de Janeiro: Editora 34, 1993. (Coleção Trans).

PEREZ, J. Da Correspondência de Spinoza. In: Cadernos Espinosanos, VII. São Paulo, 2001, p. 175-179.

SPINOZA, B. Opera. Im Augrag der Heidelberger Akademie der Wissenschaften herausgegeben von Carl Gebhardt. Heidelberg, C. Winter, 1925; 2: Auflage 1972, 4 v. 
